\title{
Revisiting pragmatic tests in the FL context: Towards interactive tests to examine speech act performance ${ }^{1}$
}

\author{
Vicent Beltrán Palanques \\ vbeltran@uji.es \\ Universitat Jaume I, Spain
}

\begin{abstract}
The aim of this study is to explore the task effect of two different research methods, namely those of interactive discourse completion tasks/tests (IDCTs) and role-play tasks (RPTs). The two research methods employed in this study adopt an interactive approach that allows participants to freely interact not only in the oral mode but also in the written mode. This paper compares the apology strategies elicited by means of IDCTs and in RPTs in terms of strategy length, amount of strategies and classification of strategies across the two elicitation techniques. Results from this comparison will be presented and discussed, and pedagogical implications suggested.
\end{abstract}

Key words: research methods, IDCTs, RPTs, apologies.

\section{INTRODUCTION}

Testing pragmatics is a relatively young field of research within interlanguage pragmatics (ILP). Although different research methods are used to conduct ILP research (see Kasper and Roever, 2005), discourse completion tests/tasks (DCTs) and role-play tasks (RPTs) are typically used. Over the years, several authors have empirically examined the two aforementioned research methods so as to improve their effectiveness (Houck and Gass 1996; Sasaki 1998; Yuan, 2001; Martínez-Flor 2006, 2013; Duan 2008; Eslami-Rasekh 2012; Beltrán-Palanques 2013). Yet, there is still a need to further explore this particular field of research to shed more light on this specific issue. According to Kasper and Roever (2005), research methods in ILP can be classified as follows: (1) observational data of spoken interaction involving authentic discourse; elicited conversation and RPTs; (2) questionnaires as written DCTs and multiple choice

\footnotetext{
${ }^{1}$ The research conducted in this article is part of the Education and Innovation research project: Proyecto de Innovación Educativa Universitat Jaume I 2779/13 Parámetros de aproximación a la evaluación de las destrezas orales en lengua inglesa: tipología, diseño de test y criterios de validación.
} 
questionnaires; (3) rating scales; (4) oral and narrative forms of self-report; (5) diaries; and (6) verbal reports. Two of the most widely employed research methods in ILP are DCTs and RPTs.

\section{I.1. Discourse completion tasks/tests (DCTs)}

DCTs involve a task that contains a description of a given situation (i.e. a prompt), and an empty space, intentionally left, in which the participant has to provide a specific utterance (Kasper and Roever 2005; Roever, 2010). Kasper (2000) distinguishes four main types that derive from the original version of the DCT, i.e. (1) the classic DCT; (2) the dialogue construction DCT; (3) the open item verbal response only; and (4) the open time free response. The classic DCT typically involves a first turn of a dialogue that serves as a stimulus, and a missing gap, which is also known as a rejoinder (Johnston et al. 1998). The second type, the dialogue construction, does not include the response of a hearer, and the gap may or may not be introduced by an interlocutor's turn. The third and fourth types do not require a construction of a dialogue. Specifically, in the third type, the open item verbal response only, involves a written verbal response, and in the fourth type, participants can provide verbal and non-verbal responses or even opt out. Additionally, other types of DCTs can also be found in the literature, such as the content-enriched DCT prompts proposed by Billmyer and Varghese (2000: 543), which might "elicit more robust external modification and elaboration than do the archetypal content-poor prompts which most DCTs studies to date have used". Other DCTs can be for instance, the free discourse completion tasks (Barron 2003), also known as the dialogue production tasks in pragmatic variation (Schneider 2008) in which two participants elaborate a dialogue, or the multiple-rejoinder DCT advanced by Cohen and Shively (2003) in which participants provide different responses over a dialogue. Furthermore, other research methods including visual aids have been developed such as the cartoon oral production tasks (Rose 2000) or interactive DCTs (IDCTs) (MartínezFlor and Usó-Juan 2011; Beltrán-Palanques, 2013) that may also incorporate enhanced photos (Martínez-Flor and Usó-Juan 2011). Finally, multimedia DCTs have also been designed, such as the computer-assisted interactive DCTs (Kuha 1997), the multimedia elicitation task (Schauer 2004, 2009), which is a computer-based system, the 
computerized extended DCTs with video prompts (Sydorenko et al. 2014), or the IDCTs performed by means of Google Docs (Beltrán-Palanques in press).

By means of DCTs, researchers may obtain a relatively large amount of data in a short period of time (Roever 2010). Nevertheless, the fact that DCTs can be administered in a short period of time does not necessarily imply that their use is not complex (Kasper and Roever 2005). DCTs are not without criticism; for example, Rose (1994) highlights the artificiality of those tests and Sasaki (1998) indicates that DCTs can be seen as a pen and paper method that resembles a typical written test. Considering these aspects, it could be to some extent questioned whether these tests might represent authentic discourse. Participants may be somehow affected by the nature of the mode in which they are asked to produce their utterances, and consequently this could have an influence on speech act production. In line with this, Golato (2003) argues that DCTs might not always provide an accurate depiction of what they would really say in an authentic oral interaction. Another aspect that may be questioned is the lack of interaction since, in most cases, DCTs only allow participants to take one turn. In an attempt to overcome this problem, some researchers have proposed different typologies of DCTs that include an interactive perspective, (e.g. Martínez-Flor and Usó-Juan, 2011; Beltrán-Palanques 2013, in press). Nevertheless, the design of the research method would depend on the purpose of the study. Despite the fact that some limitations can be identified, DCTs are widely used in the field of ILP in order to gather speech act data since, as pointed out by Kasper and Rose (2002), they show the different forms and strategies that participants employ when confronting a given situation. Furthermore, as pointed out by O'Keeffe et al. (2011: 23 their emphasis), “without this methodology, it would have been difficult if not impossible to conduct such research because some speech acts are very difficult to 'obtain' in any other way'. Hence, although some limitations can be found, DCTs are typically employed in the field of ILP to gather speech act data, and their desing would to some extent depend on the purpose of the study. 


\section{I.2. Role-play tasks (RPTs)}

RPTs are also widely used to obtain speech act data in the field of ILP, especially in foreign language (FL) contexts where obtaining authentic discourse appears to be rather complex. The RPT method, as indicated by Crookall and Saunders (1989: 15-16, their emphasis) may be seen as "a social or human activity in which participants 'take' on and 'act out' specified 'roles', often within a predefined social framework or situational blueprint (a 'scenario')". In this particular type of research method, participants are encouraged to take part in specific scenarios, perform them orally and say what they would say in such concrete situations and circumstances (Crookall and Saunders 1989; Roever 2010). Moreover, as in the case of DCTs, RPTs may contain contextual information about the context in which the simulated social encounter might occur as well as about the relationship of the participants.

According to Kasper and Dahl (1991), two main types of role-plays depending on the level of interaction can be distinguished, namely those of closed or monologic and open or interactive. Closed RPTs involve the response of one participant to a particular situation without having the response of another interlocutor, whereas open RPTs provide participants with opportunities for interacting and elaborating different turns. Thus, open RPTs can involve as many turns and discourse phases as necessary since interlocutors can interact until the communicative purpose is achieved. It seems that there is a clear advantage of open RPTs over closed RPTs because participants can communicate somehow freely and researchers can then gather further features of spoken production due to its interactive nature. However, as in the case of DCTs, their design would depend on the purposes of the study.

It is also worth mentioning that it remains uncertain whether by means of RPTs an accurate representation of authentic language use in real contexts could be provided (Kasper 2000). It is suggested that data derived from RPTs might somehow differ from that found in natural contexts (Kasper 2000; Golato 2003). Roever (2010) also indicates that natural data may differ from RPTs in the sense that RPTs are simulated scenarios and participants are aware of that fact. Then, participants might not necessarily produce 
the same utterances that they would in a real social interaction where their interaction may have an impact on real life (Roever 2010). That is to say, when performing a RPT, participants act out a given role in a simulated context rather than in a natural setting, and consequently it is not clear whether the discourse created might reflect appropriately the linguistic behaviour that might be at work in natural encounters. Another drawback that could be identified is the lack of visual information, as in most cases, researchers use audio data instead of video data. Hence, nonverbal pragmatics is not captured and consequently researchers might not gather all the information that is present in a social interaction. Despite the fact that some limitations can be identified, RPTs are still used in the field of ILP to gather oral speech act data as they allow researchers to obtain specific spoken data about the particular pragmatic aspects investigated.

\section{WRITTEN AND SPOKEN DATA: AN OVERVIEW}

Over the last decades, different researchers have carried out different studies contrasting and comparing the speech act outcomes of DCTs and RPTs. Houck and Gass (1996) examined the use of refusals as a response to other speech acts (i.e. suggestions, offers, invitations, and requests) by Japanese learners of English as a second language (SL) in both videotaped open RPTs and written DCTs. Results showed that the data obtained in the RPTs was greater since participants employed longer responses and wider use of negotiation segments than those in the written DCTs. Moreover, lower varieties of speech act realisations were found in the written data. Contrarily, Rintell and Mitchell (1989) did not find significant differences in the responses obtained by means of written DCTs and closed RPTs concerning response type. The authors compared the responses obtained from both closed RPTs and written DCTs as regards the speech acts of requests and apologies. In this study, participants were made up of both language learners of English as SL and native speakers. According to Rintell and Mitchell (1989), findings might have also been affected by the fact that closed RPTs, due to its nature, did not allow interaction between participants. Still, the responses given in the oral tasks were longer. Similar results concerning the content of the semantic formulae were found in the study conducted by Eisenstein and Bodman's (1993). The study focused on how 
the speech act of gratitude was expressed by both native speakers and non-native speakers by means of four different research methods, i.e. natural observation, oral DCTs, written DCTs, and RPTs. In comparing the four methods, results showed similar responses regarding the content of the semantic formulae. The main difference, however, lied on the level of interaction of the research methods. Also, when comparing the two types of DCTs, the oral DCT version allowed participants to take more turns than the written DCT, and consequently, longer responses were produced.

Sasaki (1998) compared the production of requests and refusals elicited by a group of Japanese students by means of written DCTs and closed RPTs. In contrasting the data obtained from the two research methods, results demonstrated that the responses differed in terms of length and content. Specifically, the responses elicited in the oral method were longer and they contained more and higher variety of semantic formulae than those in the written method. The author argued that the difference found concerning length could be related to the fact that in the oral task participants employed features of spoken language such as repetitions and hesitations. However, the types of central speech act expressions elicited in both research methods were similar. Yuan (2001) examined the production of compliment and compliment responses in various research methods, i.e. written DCTs, oral DCTs, field notes and natural conversations. Results showed that in providing the participants with only one turn in the written DCTs and oral DCTs, interaction might not take place as in the case of RPTs and natural conversations. Results also revealed that the responses in the oral DCT offered more features of natural language than those found in written DCTs. Similar results were found by Martínez-Flor (2006), who focused on the speech act of suggestions. More specifically, the author examined the task effect on two types of production methods, i.e. phone messages and emails. Results indicated that a large amount of semantic formulae were found in written DCTs. In this respect, the author stated that these results might have been affected by the fact that the oral production tasks employed in the study did only allow participants to elicit more than one turn since the type of oral task was similar to closed RPTs. Furthermore, Martínez-Flor (2006) also reported that the responses found in the written task were longer and further elaborated that those appearing in the oral task. Concerning this, the author pointed out that this might have 
been related to the fact that the written task was not a conventional pen-and-paper task since this particular task was developed via email format and that they had more time to think about their responses.

In another FL context, Duan (2008) explored the use of refusal strategies by Chinese learners of English as a FL as a response to four different situations, namely those of invitations, suggestions, offers and requests, in two different research methods, written DCTs and oral RPTs. Results revealed that no significant differences were found in terms of strategies when comparing the two research methods. Nevertheless, the author pointed out that the written DCTs appeared to show longer sentences, whereas the oral RPTs produced more natural expressions since further features of authentic spoken language such as pause fillers and broken sentences were identified. More recently, Eslami-Rasekh (2012) examined data taken from written DCTs and closed RPTs. In this particular case, the author focused on the requests strategies produced by a group of Iranian university students in their first language (L1) (i.e. Persian). Findings demonstrated that longer responses were found in the oral data, which was related to the fact that longer and greater number of alters and supportive moves were used in this the RPTs. Concerning the variety of strategies, results indicated that no differences between the two research methods were noted. However, in the written DCTs, more direct realisations were identified. Besides, the modification devices that appeared in the oral method had a softer tone, and concerning the request perspective, findings showed that the data found in the written DCTs were more hearer-oriented, whereas the oral data presented a more impersonal or collective referent. The author, then, concluded that the data obtained by means of RPTs could provide a better representation of natural speech than that gathered through written DCTs. Martínez-Flor (2013), in the Spanish context, conducted a study to investigate the task effect in learners' production of refusal strategies. In this study two different production methods purposefully designed following an interactive perspective were used: interactive written DCTs and open RPTs. The focus of this study was to compare the outcomes of the two research methods to examine the refusal responses in terms of length, amount and typology. Results demonstrated that the amount, the length and the type of refusal strategies employed were to some extent similar in both research methods. In light of such results, 
Martínez-Flor (2013) indicated that the adoption of an interactive approach in the design of the written DCTs, thereby similarly to RPTs, seemed to have positively affected participants' responses since they could negotiate meaning and use different turns, which somehow promoted the elicitation of a rich variety of refusal strategies. Finally, Beltrán-Palanques (2013) conducted a study in the Spanish context in which the speech act under investigation was that of apologies. In this particular study, following Martínez-Flor's (2013) study, an interactive approach was followed when designing both the DCTs (i.e. IDCTs) and the open RPTs. Results from this study were in line with the study conducted by Martínez-Flor (2013) since the quantity and quality of the speech act realisation of apologies were similar across the two research methods due to their interactive nature.

Considering the above sketched literature review, the purpose of this study is to examine the effect of two different research methods, IDCTs and open RPTs, on participants' pragmalinguistic apology sequences. Research questions guiding this study are the following:

- Will the data collected by means of open RPTs and IDCTs elicit similar results as regards length?

- Will the data collected by means of open RPTs and IDCTs elicit similar results as regards amount of strategies used?

- Will the data collected by means of open RPTs and IDCTs elicit similar distribution of strategies?

\section{METHODOLOGY}

\section{III.1. Participants}

This study involved 16 female adult learners whose average age was 22.5. All of them were graduate students and they were studying English as a FL, more specifically a B2.1 level course. Despite the fact that they were studying a B2.1 level course of English, the Quick Placement Test (2001) published by Oxford University Press was employed to verify their proficiency level. Results showed that participants were closer 
to the B2 level although they had still not achieved this specific level. The background questionnaire, adapted from Beltrán-Palanques (2013), showed that participants were all bilinguals (Catalan and Spanish). They have been to an English speaking country for less than 2 weeks and exclusively for tourism (e.g. holidays, visiting friends). Furthermore, half the participants had been studying English not only at school, higher school, and university, but also in some private schools. Participants were arranged in pairs so as to outperform the written and oral tasks, and then only 8 out of 16 played the role of apologiser while the remaining 8 participants were asked to produce other speech acts so as to interact in the given scenarios. Specifically, they performed mainly complaints and requests. Nevertheless, this is beyond the scope of the present study and therefore no attention will be paid to this particular issue.

\section{III.2. Pragmatic aspect under investigation}

According to Austin's (1962) classification of illocutionary acts, apologies fall into the category of behabitives, and Searle (1979) assigns this particular speech act to the category of expressives. Searle (1979: 15) indicates that apologies "express the psychological state specified in the sincerity condition about a state of affairs specified in the propositional content". Leech (1983), however, classifies this particular speech act within the convivial speech act type since its illocutionary goal coincides with the social goal, specifically, that of maintaining harmony between the speaker and the hearer in which there is some benefit for the hearer and some cost for the speaker. Aijmer (1996) indicates that apologies are strategies that are used to convey a particular communicative goal, which requires an utterance which purpose is to "set things right (Olshtain and Cohen 1983: 20)", and they are used in situations in which a speaker commits an action that damages another person.

Therefore, at least two participants need to take part in an apology sequence, the offender or hearer and the offended or hearer. Apologies are moves that are typically employed to solve a problem between at least two participants, i.e. the speaker and the hearer, and restore harmony between them. Hence, an apology situation involves a participant uttering an apology that is addressed towards the offended participant in 
order to restore problems as well as to re-establish harmony between them (Holmes 1995). By apologising, the speaker seems to understand the situation and accepts that an error has been committed. Moreover, it could be suggested that in a real situation, the speaker might apologise and negotiate the apology with the hearer, and the hearer may accept or reject the speaker' apology/apologies. In a situation in which the apology/apologies is/are accepted, participants might restore to some extent the harmony between them. In addition to this, there are also some other factors that could influence offenders' assumption of responsibility (Olshtain and Cohen 1983). For example, the perception of the degree of the severity of the offense may play an important role. The speaker might not necessarily see a violation of a social norm or an inappropriate act in his/her behaviour (Olshtain and Cohen 1983), or perhaps the speaker might choose to emphasise his or her innocence (Trosborg 1987), and then, not take any responsibility. Furthermore, other influential factors can also play a crucial role in the apology sequence such as age, degree of social distance and power between the participants.

It seems therefore that the speech act of apologies is a rather complex speech act that involves different factors such as understanding that an error has been committed. This could happen in real-life interactions, since the speaker might decide not to apologise, as he/she does not perceive that damage has been caused, or simply because the speaker does not want to apologise. In line with this, it could also be argued that personality traits, the real relationship between/among participants, as well as the possible consequences, or at least, the perceived consequences, could also affect the speakers' decision. In a simulated situation, however, participants might be asked to for example apologise in a given situation, and therefore, they would accomplish the task as required, although it is difficult to know whether he/she would act in the same way in a real interaction.

\section{III.3. Research methods}

The research methods used in this study were open RPTs and IDCTs. These two research methods were purposefully designed following an interactive perspective in 
order to allow participants to freely interact in the two tasks. For the purposes of the present study, the research methods used (See Appendix A for the open RPTs and Appendix B for the IDCTs) were the same used by Beltrán-Palanques (2013). The two elicitation techniques included a description of the roles and the contexts of each situation in order to help participants understand each scenario appropriately. The same scenarios were used in the RPTs and IDCTs in order to compare the task effect. The scenarios were designed taking into account the target group of the study, participants' sociocultural context, the setting in which they are administered (Beltrán-Palanques 2013), participants' familiarity with the roles (Trosborg 1995) and with the context (Hudson et al. 1995).

The open RPTs (see Appendix A) and the interactive written IDCTs (see Appendix B) used in this study consist of eight situations which were classified as occurring in the following contexts, namely those of university (i.e. situations 2, 5, 6 and 8), bookshop (i.e. situation 1), students' flat (i.e. situation 3), language school (i.e. situation 4), and theatre (i.e. situation 7). Furthermore, the situations were designed taking into account the sociopragmatic features of social status (i.e. hear-dominant and equal), social distance (i.e. acquaintance and stranger) and severity of offence (i.e. high and low) (Brown and Levinson 1987). Finally, it is also important to mention that some of the situations that were adapted from the studies conducted by from Afghari, (2007), Nureddeen (2008) and Flores-Salgado (2011).

\section{III.4. Procedure and data analysis}

Data for this study was collected by means of open RPTs and IDCTs. Due to the interactive nature of the two research methods, participants were randomly assigned in pairs, and each pair performed both tasks, first the RPTs and then the DCTs. Data was collected in two different phases, the first phase was conducted in the second week of the course, and the second phase during the third week of the course. In both cases, the tasks were conducted in the room where the instruction used to take place. Participants were distributed into different time slots, so during the completion of the tasks, the two participants and the teacher - who is the researcher of this study - were alone in the 
room. It is also important to note that in order to avoid time constrains, ample time was provided to perform the different tasks. Then, the two tasks were performed at the very beginning of the course, i.e. the second and the third week, and participants did not receive pragmatic instruction regarding the speech act of apologies in the FL course before administrating the tests. After conducting the study, participants were provided with instruction since the results of the study were also used for pedagogical purposes.

In order to classify the different apology strategies, a taxonomy advanced by BeltránPalanques (2013) based on previous research on apologies (Olshtain and Cohen 1983; Blum-Kulka, et al. 1989; Trosborg 1995) was employed. As shown in Table 1, the taxonomy is divided into three main parts, namely those of "Illocutionary Force Indicating Device (IFID)", “Assuming Responsibility” and "Compensating the Other".

\begin{tabular}{|c|c|c|}
\hline Strategy & Type & Example \\
\hline $\begin{array}{l}\text { IFID } \\
\text { Apologising }\end{array}$ & $\begin{array}{l}\text { Offer an apology } \\
\text { Feel obliged to apologise } \\
\text { Regret } \\
\text { Request for forgiveness }\end{array}$ & $\begin{array}{l}\text { I apologise } \\
\text { I should/must apologise } \\
\text { I'm sorry } \\
\text { Please, forgive me }\end{array}$ \\
\hline \multicolumn{3}{|l|}{ Assuming Responsibility } \\
\hline $\begin{array}{l}\text { Accepting the situation } \\
\text { Showing empathy }\end{array}$ & $\begin{array}{l}\text { Acceptance } \\
\text { Understanding the error }\end{array}$ & $\begin{array}{l}\text { You're (completely) right; I } \\
\text { (really have to) accept/ admit it/ } \\
\text { that; I (totally/ really) screw it } \\
\text { up } \\
\text { I see what you mean...; } \\
\text { I see/ understand your point of } \\
\text { view }\end{array}$ \\
\hline Lack of intention & Showing feelings & $\begin{array}{l}\text { I feel bad about what happened; } \\
\text { I feel awful/ bad/guilty } \\
\text { I didn't mean to do that/ hurt } \\
\text { you; It wasn't my intention }\end{array}$ \\
\hline Justifying the situation & Internal & $\begin{array}{l}\text { I couldn't come earlier.../ I } \\
\text { couldn't make it. }\end{array}$ \\
\hline & External & $\begin{array}{l}\text { It was raining a lot; my car } \\
\text { broke down; there was a } \\
\text { problem..; I couldn't call text } \\
\text { you to tell you that }\end{array}$ \\
\hline Compensating the Other & & \\
\hline
\end{tabular}




\begin{tabular}{|l|l|l|}
\hline Promise of forbearance & Forbearance & $\begin{array}{l}\text { It won't happen again } \\
\text { Repair the situation }\end{array}$ \\
& $\begin{array}{l}\text { Offering } \\
\text { Requesting }\end{array}$ & $\begin{array}{l}\text { I will/can/could do it for you. } \\
\text { would like to know how I can } \\
\text { compensate you. } \\
\text { Why don't we get started? }\end{array}$ \\
\hline
\end{tabular}

Table 1. Taxonomy on the speech act of apologies (Beltrán-Palanques 2013: 47-48)

This taxonomy is concurred with most apology classifications (Olshtain and Cohen 1983; Blum-Kulka et al. 1989; Trosborg 1995) which also include direct semantic strategies to offer an apology, speaker's assumption of the responsibility, and a set of semantic strategies that might show speaker's concern towards the error and/or the mistake, as well as some strategies that can be employed to compensate the hearer. In short, the present taxonomy includes the basic strategies that may be used when performing an apology and they can be combined to better express the communicative goal. Nevertheless, it is worth mentioning that further categories of strategies could be identified or other taxonomies may classify apology strategies in a different manner.

\section{RESULTS AND DISCUSSION}

This section presents the results and discussion for the three research questions that guided this study. More specifically, the research questions of this study focused on the length, amount and distribution of apology strategies across the two research methods. The results were analysed using the Paired T-test. Table 2 shows the results as regards length and amount of apology strategies.

\begin{tabular}{|l|l|l|l|l|}
\hline$N$ & $\begin{array}{l}\text { IDCT } \\
\text { Length }\end{array}$ & $\begin{array}{l}\text { RPT } \\
\text { Length }\end{array}$ & $\begin{array}{l}\text { IDCT } \\
\text { Amount }\end{array}$ & $\begin{array}{l}\text { RPT } \\
\text { Amount }\end{array}$ \\
\hline Mean & 855.50 & 873.88 & 48.50 & 51.25 \\
\hline Standard deviation & 27.553 & 29.240 & 5.372 & 4.979 \\
\hline $\mathrm{t}$ & & 3.973 & & 5.227 \\
\hline Sig. Bilateral & & .005 & \multicolumn{2}{|c|}{.001} \\
\hline
\end{tabular}

Table 2. Results as regards length and amount across IDCTs and RPTs. 
The first research question focused on whether data collected by means of open RPTs and IDCTs would elicit similar results as regards length. Results revealed that the mean of the length in the IDCTs was 855.50 whereas that of RPTs was 873.88 . It was found that the standard deviation of the IDCTs was 27.553 and that of RPTs was 29.240. The $\mathrm{t}_{8}$ value found was 3.973 and the Sig. bilateral was 0.005 , i.e. $\mathrm{p}$ value $=0.005 \leq \alpha 0.05$, revealing that the research method employed the data collection procedure affected the length of the data elicited. This would imply, in this specific study, that despite the fact that the two research methods followed an interactive perspective differences across the two instruments were found, being the responses elicited in the oral mode longer than those found in the written data. The second research question in this study was concerned with whether the data collected by means of open RPTs and IDCTs would elicit similar results concerning the amount of strategies. Results showed that the mean found as regards the amount of strategies elicited in the IDCTs was 48.50 while in the RPTs was 51.25. The standard deviation in the case of the IDCTs was 51.25 and 4.979 in the RPTs. The $t 8$ value obtained was 5.227 and the Sig. bilateral was .001 , i.e. i.e. $p$ value $=0.001 \leq \alpha 0.05$. It was therefore identified that the difference was statistically significant. Dissimilar amount of semantic formulae was found when comparing the data derived from the IDCTs and the open RPTs. These results were similar to the findings concerning the first research question. That is to say, regardless of participants' opportunities for interaction, the research method used seemed to have affected the results obtained since there were statistical differences. Results seemed to suggest that that amount of strategies elicited in the RPTs were slightly greater than in the IDCTs.

Finally, the third research question focused on the distribution of the strategies across the two research methods. In order to examine the distribution of the strategies, the taxonomy presented by Beltrán-Palanques (2013) was used. To examine this aspect, a Paired T-test was applied taking into account the three main categories identified in the taxonomy used for the purposes of this study, i.e. IFID, Assuming Responsibility and Compensating the Other. Table 3 shows the results as regards the distribution of the strategies across the two research methods. 


\begin{tabular}{|l|l|l|}
\hline$N$ & IDCT & RPT \\
3 & Distribution & Distribution \\
\hline Mean & 89.33 & 84.67 \\
\hline Standard deviation & 11.590 & 7.767 \\
\hline $\mathrm{t}$ & & 2.000 \\
\cline { 1 - 1 } Sig. Bilateral & & .184 \\
\hline
\end{tabular}

Table 3. Results as regards the ddistribution of apology strategies across the two research methods.

In this case, the purpose was to explore the distribution of the strategies considering the taxonomy advanced, which was divided into three main parts, to whether participants' apologies distribution across the two research methods were consistent. The mean found concerning the amount of strategies elicited in the IDCTs was 89.33 whereas in the RPTs was 84.67. The IDCTs showed a standard deviation of 11.590 and the RPTs of 7.767. The $t_{3}$ value obtained was 2.000 and the Sig. bilateral was .184, being the $p$ value set at $\alpha 0.05$. It was therefore concluded that the results was not statistically significant. This finding could be related to the fact that both research methods offered participants with similar opportunities for performing their tasks and that both followed an interactive approach. Interestingly, the results found as regards the third research question revealed that there were no differences as regards the distribution of the strategies, but there were differences concerning the length of strategies and amount of strategies, being greater in both cases in the RPTs. This could be related to the fact that in the oral mode, participants tended to produce longer strategies and more strategies to better convey their communicative purpose and make themselves understood. Also, in the oral mode, participants might, for example, employ features of spoken language such as repetitions and hesitations (Sasaki 1998), however, in this study, oral features such as repetitions (e.g. I, I), or hesitation were not considered.

These findings appear to partially contradict previous research in which interactive research methods were employed (Beltrán-Palanques 2013; Martínez-Flor 2013). Particularly, the studies conducted by Beltrán-Palanques (2013) and Martínez-Flor (2013) focused also on the length, amount and distribution of two different speech acts, apologies and requests, respectively. In those studies statistical differences across the 
two research methods were not identified. Moreover, in both studies, the research methods were characterised for following an interactive approach. The differences as regards length and amount could be related to the fact that in the spoken mode participants might have more opportunities to hesitate, repeat themselves (Sasaki, 1998), as well as to use false starts and other characteristics of the spoken discourse which are not present in the written mode. Nevertheless, in this study, those aspects were not taken into account as they could influence the results. Regarding the distribution of strategies, the results of this study were consistent with previous research in which no statistical differences were found (Beltrán-Palanques, 2013; Martínez-Flor, 2013). However, results showed that regardless of having a similar distribution of strategies, the length and the amount of strategies elicited was similar, possibly related to the fact that participants tended to use longer and a greater quantity of strategies to research their communicative purpose in the oral mode.

In light of the results obtained, it could be suggested that the level of interaction of the research methods would not be the only aspect to take into account when designing research methods. Other aspects such as participants' ability to perform each task as well as personality traits and participants' psychological conditions when taking the tests could also play a role in the completion of tasks. Then, this may imply that perhaps there are further aspects that could affect participants' speech act elicitation, that is to say, external factors to the actual research method. Furthermore, despite the effort made to provide an interactive written instrument, differences between acting out in the spoken mode and written mode might appear which in turn could be logical since there are differences between written and spoken discourses. Finally, it is important to state that this study could have been enriched by means of retrospective verbal reports so as to further obtain insights into participants' thoughts, but unfortunately, due to time constraints, they were not included for the purposes of this study (see for a review Félix-Brasdefer, 2010; Beltrán-Palanques, 2014), which in this case would have been beneficial to examine the differences found. The main limitations of this study are the number of participants as well as having only female participants, and thereby these limitations should be taken into account for further research. 


\section{CONCLUSION}

The purpose of this study was to compare two different research methods, specifically those of RPTs and IDCTs. The two research methods, which were previously used by Beltrán-Palanques (2013), followed an interactive perspective. It was believed that in order to appropriately compare the outcomes of the two research methods, participants should be given with the same opportunities for interaction. In this specific case, the purpose was to explore whether the interactive nature of the traditional DCT could have an effect on participants' elicitation of apologies. Further conditions were taken into account, for example, the same scenarios were used in both research methods and they were completed in pairs; being in both cases the same pair of participants. This study showed that albeit the two research methods were valid to elicit the speech act data of apologies in specific controlled situations from an interactive perspective, significant differences were found as regards the length of utterances and amount of apology strategies. However, no differences were found concerning the amount of strategies as well as the typology.

Finally, it is worth adding that from the study presented above, some future research and pedagogical suggestions can be provided. On the one hand, it seems that it would be necessary to further develop research methods that foster interaction among participants, if the aim is that of capturing interaction, as well as examine data taking into account the whole discourse, that is to say, analysing not only the speech act investigated, but also all the different speech acts appearing the interaction, as well as how participants negotiate communicate, and make themselves understood over the different turns. Ideally, this type of research methods should be used in combination with verbal reports in order to gather further data (Félix-Brasdefer 2010; BeltránPalanques 2014). On the other hand, these two research methods can also be used in the language classroom to assess pragmatic competence as part of a process of instruction of speech acts. Moreover, these research methods could also be used as diagnostic tests before teaching specific speech acts as they could provide teachers with insights about learners' pragmatic knowledge. Hence, the pedagogical value of these research methods 
should not be ignored as they can serve not only to assess pragmatic knowledge in a final stage of instruction, but also as a diagnostic test.

\section{REFERENCES}

Afghari, A. 2007. "A sociopragmatic study of apology speech act realization patterns in Persian”. Speech Communication, 49, 177-185.

Aijmer, K. 1996. Conversational Routines in English. London: Longman.

Austin, J. 1962. How to do Things with Words. Cambridge MA: Harvard University Press.

Barron, A. 2003. Acquisition in Interlanguage Pragmatics: Learning How to Do Things with Words. Amsterdam: John Benjamins Publishing Company.

Beltrán-Palanques, V. (2013). Exploring Research Methods in Interlanguage Pragmatics: A Study Based on Apologies. Saarbrücken: Lap Lambert Academic Publishing GmbH KG.

Beltrán-Palanques, V. (2014). "Methodological Issues in Interlanguage Pragmatics: Some Food for Thought". In Alcaraz-Mármol, G. and M. M. Jiménez-Cervantes (Eds.) Studies in Philology: Linguistics, Literature and Cultural Studies in Modern Languages. Newcastle upon Tyne: Cambridge Scholars Publishing, 239253.

Beltrán-Palanques, V. (in press). "Synchronous Computer-Mediated Communication in ILP Research: A Study Based on the ESP Context". In Martín-Monje, E., I. Elorza and B. García-Riaza (Eds.) Technology-Enhanced Language Learning for Specialized Domains: Practical Applications and Mobility. London: Routledge.

Billmyer , K., and Varghese, M. 2000. "Investigating instrument-based pragmatic variability: Effects of enhancing discourse completion tests". Applied Linguistics, $21(4), 517-552$.

Blum-Kulka, S., House, J., and Kasper, G. 1989. Cross-Cultural Pragmatics: Requests and Apologies. Norwood, NJ: Ablex.

Brown and Levinson.1987. Politeness: Some Universals in Language Usage. Cambridge: Cambridge University Press.

Cohen, A., and Shively, R. 2003. "Measuring speech acts with multiple rejoinder DCTs". Language Testing Update, 32, 39-42.

Crookall, D., and Saunders, D. 1989. "Towards an integration of communication and simulation". In Crookall, D. and D. Saunders (Eds.) Communication and 
Simulation: From Two Fields to One Theme. Clevedon: Multilingual Matters, 329.

Duan, A. W. 2008. "The comparison between written DCT and oral role-plays in investigation upon English refusal strategies by Chinese EFL students". Sino-US English Teaching, 5 (10), 8-18.

Eisenstein, M., and Bodman, J. 1993. "Expressing gratitude in English.” In Kasper, G. and S. Blum-Kulka (Eds.) Interlanguage Pragmatics.Oxford: Oxford University Press, 64-81.

Eslami-Rasekh, A. 2012. "Eliciting Persian requests: DCT and role play data". World Journal of Education, 2 (3), 80-86.

Félix-Brasdefer, J. C. 2010. "Data collection methods in speech act performance". In Martínez-Flor, A. and E. Usó-Juan (Eds.) Speech Act Performance. Theoretical, Empirical and Methodological Issues. Amsterdam: John Benjamins Publishing Company, 41-56.

Flores-Salgado, E. 2011. The Pragmatics of Requests and Apologies. Developmental Patterns of Mexican Students. John Benjamins Publishing Company.

Golato, A. 2003. "Studying compliment responses: A comparison of DCTs and recording of naturally occurring talk". Applied Linguistics, 21 (1), 90-121.

Holmes, J. 1995. Women, Men and Politeness. New York: Longman.

Houck, N., and Gass, S. 1996. "Non-native refusal: A methodological perspective". In Gass, S. and J. Neu (Eds.) Speech Acts Across Cultures. Berlin: Mouton de Gruyter, 45-64.

Hudson, T., Detmer, E., and Brown, J. 1995. Developing Prototypic Measures of Cross-Cultural Pragmatics (Technical Report, 7). Honolulu: University of Hawai'i .

Johnston, B., Kasper, G., and Ross, S. 1998. "Effect of rejoinders in production questionnaires". Applied Linguistics, 19 (2), 157-182.

Kasper, G. 2000. "Data collection in pragmatics research". In Spencer-Oatey, H. (Ed.), Culturally Speaking. Managing Rapport through Talk across Cultures. London: A\&C Black, 316-341.

Kasper, G. and Dahl, M. 1991. "Research methods in interlanguage pragmatics". Studies in Second Language Acquisition, 13 (2), 215-247.

Kasper, G. and Roever, C. 2005. "Pragmatics in Second Language Learning". In Hinkel, E. Handbook of research in second language learning and teaching. Mahwah, NJ: Erlbaum, 317-334.

Kasper, G. and Rose, K. Pragmatic Development in a Second Language (Language Learning Monographs Series). Oxford: Blackwell. 
Kuha, M. 1997. "The Computer-Assisted Interactive DCT: A Study in Pragmatics Research Methodology". In Bouton, L. F. (Ed.), Pragmatics and Language Learning (Vol. 8). Urbana-Champaign: Division of English as an International Language, University of Illinois, 99-127.

Leech, G. 1983. Principles of Pragmatics. London: Longman.

Martínez-Flor, A. 2006. "Task effects on EFL learners' production of suggestions: A focus on Elicited phone messages and emails". Miscelánea: A Journal of English and American Studies, 33, 47-64.

Martínez-Flor, A. 2013. "Learners' production of refusals: Interactive written DCT versus oral role-play". In Martí, O. and P. Salazar (Eds.) Refusals in Instructional Contexts and Beyond. Amsterdam: Rodopi, 175-211.

Martínez-Flor, A. and Usó-Juan, E. 2011. "Research methodologies in pragmatics: Eliciting refusals to requests". ELIA: Estudios de lingüística inglesa aplicada, 11, 47-87.

Nureddeen, F. 2008. "Cross cultural pragmatics: Apology strategies in Sudanese Arabic". Journal of Pragmatics, 40, 279-306.

O'Keeffe, A., B. Clancy, and S. Adolphs. 2011. Introducing Pragmatics in Use. London: Routledge.

Olshtain, E. and Cohen, A. 1983. "Apology: A speech act set”. In Wolfson, N. and E. Judd (Eds.) Sociolinguistics and Second Language Acquisition. Rowley MA: Newbury House, 18-35.

Oxford Quick Placement Test. 2001. Oxford: Oxford University Press.

Rintell, E. and Mitchell, C. "Studying requests and apologies: An inquiry into method". In Blum-Kulka, S., J. House, and G. Kasper (Eds.), Cross-cultural pragmatics: Requests and apologies. Norwood, NJ, The US: Ablex, 248-272.

Roever, C. 2010. "Researching Pragmatics". In Paltridge, B., and A. Phakiti (Eds.) Continuum Companion to Research Methods in Applied Linguistics. London: Continuum International Publishing Group, 240-255.

Rose, K. 1994. "On the validity of DCTs in non-western contexts". Applied Linguistics, 22, 1-14.

Rose, K. 2000. "An exploratory cross-sectional study of interlanguage pragmatic development". Studies in Second Language Acquisition, 22 (1), 27-67.

Sasaki, M. 1998. "Investigating ELF students' production of speech acts: A comparison of production questionnaires and role plays". Journal of Pragmatics, 30 (4), 457484.

Schauer, G. 2004. "May you speak louder maybe? Interlanguage pragmatic development in requests". In Foster-Cohen, S., M. Sharwood-Smith, A. Sorace 
and M. Ota (Eds.), EUROSLA Yearbook Amsterdam: John Benjamins Publishing Company, 253-273.

Schauer, G. 2009. Interlanguage Pragmatic Development: The Study Abroad Context. London: Continuum.

Schneider, K. 2008. "Small Talk in England, Ireland, and the USA". In Schneider, K. and A. Barron (Eds.) Variational Pragmatics: A Focus on Regional Varieties in Pluricentric Languages. Amsterdam: John Benjamins Publishing Company, 99139.

Searle, J. 1979. Expression and Meaning: Studies in the Theory of Speech Acts. Cambridge : Cambridge University Press.

Sydorenko, T., Maynard, C. and Guntly, E. 2014. "Rater behaviour when judging language learners' pragmatic appropriateness in extended discourse". TESL Canada Journal, 32 (1), 19-41.

Trosborg, A. 1987. "Apology strategies in native/non-native speakers of English". Journal of Pragmatics, 11 (1), 147-167.

Trosborg, A. 1995. Interlanguage Pragmatics: Requests, Complaints, and Apologies. Berlin: Walter de Gruyter.

Yuan, Y. 2001. "An inquiry into empirical pragmatics data-gathering methods: Written DCTs, oral DCTs, field notes, and natural conversations". Journal of Pragmatics, 33, 271-292. 


\section{Appendix A}

\section{Open role-play tasks}

Read the following communicative situations and perform them.

Scenario 1:

Student A:

You are a university student. You are in a bookshop in the city centre looking for a book. All of a sudden, another girl/boy, who is more or less your age, walks into you accidently. What would you say?

Student B:

You are university student. You are in a bookshop with a friend. You are having a look at a book when your friend calls you. Then you turn around and run into an unknown girl/boy who is more or less your age. What would you say?

Scenario 2:

Student A:

You are a professor who has asked his/her students to submit a paper. Although there is a deadline, some students have not delivered their work yet. While you are in your office hours, a student that you know from previous years comes there to talk to you. What would you say?

Student B:

You are student at university. You have been asked to prepare a paper and deliver it on a particular day but you haven't done it. Since you know that professor from previous academic years, you decide to talk to her/him. What would you say? 
Scenario 3:

Student A:

You share a flat with another girl/boy. You know that your flatmate has organised a dinner at your place.

However, you will not go because you will be out for the weekend. Once you get back home, you realise that your flatmate hasn't tidied up the living-room. What would you say?

Student B:

You share a flat with another girl/boy. While your flatmate is out for the weekend, you have a dinner at the apartment with some friends. However, you haven't tidied up the living-room yet and it is rather untidy. What would you say?

Scenario 4:

Student A:

You work in a language school. You have asked one of your employees to bring you a textbook that you would like to use in a course that you will teach in two weeks. However, she/he hasn't done it. What would you say?

Student B

You are a graduate student who works at a language school. Your boss has asked you to bring her a textbook. You know that she/he will need it for a course that she/he will teach in two weeks, but you know that she wanted to have it today. However, you have forgotten it at home. What would you say? 
Scenario 5:

Student A:

You are a university student. A classmate that you know from previous courses has been ill for some days, and because of this she/he has asked you if you could lend her your notes. You agree on that but you tell her/him that you need them back on Friday morning because you have an exam on Monday. What would you say?

Student B:

You are a university student. You have been ill for some days and one of your classmates lent you her/his notes. You have told her/him that you will bring the notes on Friday morning since you both have to study for the exam you have on Monday. Unfortunately, you leave the notes at home. What would you say?

Scenario 6:

Student A:

You are the language coordinator at the language centre of a university. You have to interview a girl/boy for a job. However, she/he is late and you have been waiting for her for about 25 minutes. What would you say?

Student B:

You have finished your English Studies degree. You have an interview with the language coordinator of the language centre of a university at 10 a.m. but since you are caught in a traffic jam you arrive around 25 minutes late. What would you say? 
Scenario 7:

Student A:

You are a rather famous actress/actor who performs monologues in theatres. While performing your monologue, the mobile of someone from the audience starts to ring. You don't pay much attention to that fact. What would you say?

Student B:

You and a friend go to the theatre to see a monologue. While the actress/actor is performing the monologue, your mobile phone starts to ring. You can't find it to turn it off. Eventually, you manage to do it. What would you say?

Scenario 8:

Student A:

You have registered on a language course at the university. You have attended all the sessions of the course, so you have all the notes. One day, a student that you do not know sits next to you. At the end of the session she/he suggests going for a coffee. While you are showing her/him the notes, she/he accidently drops her/his coffee on them. What would you say?

Student B:

You have registered on a language course at the university but you have not attended any sessions so you do not have the notes. The first day you go to class, you sit next to another student. After the session, you suggest going for a coffee. While she/he is showing you her notes, you accidently drop your coffee on them. What would you say? 


\section{Appendix B}

\section{Interactive discourse completion task}

Read the following communicative situations and perform them.

Scenario 1:

Student A:

You are a university student. You are in a bookshop in the city centre looking for a book. All of a sudden, another girl/boy, who is more or less your age, runs into you accidently. What would you say?

Student B:

You are university student. You are in a bookshop with a friend. You are having a look at a book when your friend calls you. Then you turn around and run into an unknown girl/boy who is more or less your age. What would you say?
A:
$\mathrm{B}$ :
A
$\mathrm{B}$
A:
B:

Scenario 2:

Student A:

You are a professor who has asked his/her students to submit a paper. Although there is a deadline, some students have not delivered their work yet. While you are in your office hours, a student that you know from previous years comes there to talk to you. What would you say?

Student B:

You are student at university. You have been asked to prepare a paper and deliver it on a particular day but you haven't done it. Since you know that professor from previous academic years, you decide to talk to her/him. What would you say?

A:

B:

A:

B

A

B

A

B: 
Scenario 3:

Student A:

You share a flat with another girl/boy. You know that your flatmate has organised a dinner at your place. However, you will not go because you will be out for the weekend. Once you get back home, you realise that your flatmate hasn't tidied up the living-room. What would you say?

Student B:

You share a flat with another girl/boy. While your flatmate is out for the weekend, you have a dinner at the apartment with some friends. However, you haven't tidied up the living-room yet and it is rather untidy. What would you say?
A:
$\mathrm{B}$ :
A:
$\mathrm{B}$ :
A:
$\mathrm{B}$ :
A:
$\mathrm{B}$ :

Scenario 4:

Student A:

You work in a language school. You have asked one of your employees to bring you a textbook that you would like to use in a course that you will teach in two weeks. However, she/he hasn't done it. What would you say?

Student B:

You are a graduate student who works at a language school. Your boss has asked you to bring her a textbook. You know that she/he will need it for a course that she/he will teach in two weeks, but you know that she wanted to have it today. However, you have forgotten it at home. What would you say?
A:
$\mathrm{B}$
A:
$\mathrm{B}$ :
A:
B:
A:
$\mathrm{B}$ : 
Scenario 5:

Student A:

You are a university student. A classmate that you know from previous courses has been ill for some days, and because of this she/he has asked you if you could lend her your notes. You agree on that but you tell her/him that you need them back on Friday morning because you have an exam on Monday. What would you say?

Student B:

You are a university student. You have been ill for some days and one of your classmates lent you her/his notes. You have told her/him that you will bring the notes on Friday morning since you both have to study for the exam you have on Monday. Unfortunately, you leave the notes at home. What would you say?

A:

$\mathrm{B}$

A:

$\mathrm{B}$ :

A:

$\mathrm{B}$ :

A:

B:

Scenario 6:

Student A:

You are the language coordinator at the language centre of a university. You have to interview a girl/boy for a job. However, she/he is late and you have been waiting for her for about 25 minutes. What would you say?

Student B:

You have finished your English Studies degree. You have an interview with the language coordinator of the language centre of a university at $10 \mathrm{a} . \mathrm{m}$. but since you are caught in a traffic jam you arrive around 25 minutes late. What would you say?

A:

B:

A:

B:

A:

B:

A:

B: 
Scenario 7:

Student A:

You are a rather famous actress/actor who performs monologues in theatres. While performing your monologue, the mobile of someone from the audience starts to ring. You don't pay much attention to that fact. What would you say?

Student B:

You and a friend go to the theatre to see a monologue. While the actress/actor is performing the monologue, your mobile phone starts to ring. You can't find it to turn it off. Eventually, you manage to do it. What would you say?

A:

B:

A:

$\mathrm{B}$

A

$\mathrm{B}$ :

A:

B:

Scenario 8:

Student A:

You have registered on a language course at the university. You have attended all the sessions of the course, so you have all the notes. One day, a student that you do not know sits next to you. At the end of the session she/he suggests going for a coffee. While you are showing her/him the notes, she/he accidently drops her/his coffee on them. What would you say?

Student B:

You have registered on a language course at the university but you have not attended any sessions so you do not have the notes. The first day you go to class, you sit next to another student. After the session, you suggest going for a coffee. While she/he is showing you her notes, you accidently drop your coffee on them. What would you say?
A:
$\mathrm{B}:$
A:
B:
A:
B:
A:
B: 
Received: 10 January 2014

Accepted: 22 September 2015

Cite this article as:

Beltrán-Palanques, V. 2015. "Revisiting pragmatic tests in the FL context: towards interactive tests to examine speech act performance". Language Value 7, 61-90. Jaume I University ePress: Castelló, Spain. http://www.e-revistes.uji.es/languagevalue.

DOI: http://dx.doi.org/10.6035/LanguageV.2015.7.5

ISSN 1989-7103

Articles are copyrighted by their respective authors 